\title{
Estação Meteorológica Portátil com Cultura Maker Interdisciplinar para Ensino de Física e Programação de Computadores
}

\begin{abstract}
Larissa Melo, Vitor Bremgartner, Daniel Souza
Instituto Federal do Amazonas (IFAM) - Campus Manaus Distrito Industrial

Av. Danilo Areosa, Distrito Industrial. Manaus - AM - Brasil

Abstract. Teaching Physics can be considered difficult due to so many calculations, graphs and numbers. Sometimes, the ability to associate formulas and theoretical content with everyday life does not happen clearly for students. In addition, teaching Computer Programming is also difficult for students, as they often lack the skills of solving problems using a computer. Therefore, the objective of this work is to facilitate the teaching of Physics and Computer Programming through the maker culture, in the do-it-yourself (DIY) process. As a case study, we created a portable meteorological station with Arduino, so that students could relate Thermodynamics to Computer Programming, seeking to improve the way of reasoning and visibility with the help of theoretical Physics, Maker Culture and everyday life. In this experiment, second-year High School students of a technical course in Electronics participated from Federal Institute of Amazonas Campus Manaus Distrito Industrial. The results obtained and the report of these experiences show the feasibility of the proposal.
\end{abstract}

Resumo. O ensino de Física pode ser considerado difícil devido a tantos cálculos, gráficos e números. Às vezes, a capacidade de associação das fórmulas e do conteúdo teórico com o cotidiano não acontece de forma clara pra os alunos. Além disso, o ensino de Programação de Computadores também se torna dificil para os alunos, pois muitas vezes lhes faltam habilidades de resolverem problemas por meio de um computador. Logo, o objetivo deste trabalho é facilitar o ensino de Física e Programação de Computadores por meio da Cultura Maker, no processo faça-você-mesmo (DIY). Como estudo de caso, criamos uma estação meteorológica portátil com Arduino, de forma que os alunos pudessem relacionar assuntos de Termodinâmica com Programação de Computadores, buscando melhorar a forma de raciocínio e visibilidade com o auxílio da Física teórica, a Cultura Maker e o cotidiano. Nesse experimento, participaram alunos do segundo ano de um curso técnico de Ensino Médio em Eletrônica do Instituto Federal do Amazonas Campus Manaus Distrito Industrial. Os resultados obtidos e o relato das experiências mostram a viabilidade da proposta.

\section{Introdução}

Captar a atenção e o interesse dos estudantes para aprender o conhecimento teórico ainda é um grande desafio na Educação, pois nas disciplinas como Física o conhecimento somente é passado em forma de textos e cálculos, dessa forma tornando o ensino e o aprendizado árduo (Santos; França; Santos, 2007). Uma forma de mudar esse fato é combinando o ensino teórico e a prática laboratorial, aplicando métodos eficazes, como por exemplo, a Cultura (ou Movimento) Maker (Resnick, 2020). No caso da disciplina de Física, sabe-se que a motivação para aprendê-la tem vários fatores, como questões intrapessoais que levam o aluno a se empenhar mais na aprendizagem de 
certos assuntos, ou seja, o ensino teórico adquirido pelo aluno e sua capacidade de absorção atrelada a experiências práticas podem trazer ótimos resultados, especialmente se essas experiências forem feitas pelos próprios alunos.

$\mathrm{Na}$ disciplina de Física, o objetivo principal é a compreensão do mundo, a valorização do conhecimento e a contextualização da Física como ciência e tecnologia. Apesar desses fatores, a Física tem sido apresentada aos alunos de forma engessada e esse processo de ensino esconde a verdadeira ciência, não ocorrendo a aprendizagem significativa (Vidal, 2018). Logo, o ensino da Física é visto como pouco atrativo e até mesmo desmotivador, onde tal fator faz com que os alunos tenham uma deficiência na sua formação científica-cultural, isto porque não se utiliza de elementos instigantes no processo de aprendizagem (Mourão, 2018). Principalmente nas escolas públicas de Ensino Fundamental e Médio tem-se o ensino teórico, porém na maioria das vezes sem aulas práticas por conta da deficiência de recursos. Logo, não é diferente nas aulas de Física, onde o aluno perde o interesse, principalmente aqueles que não têm muita aptidão com números e cálculos.

Sendo assim, ao se trabalhar com a Cultura Maker para o desenvolvimento de algum projeto interdisciplinar, os alunos estarão sendo introduzidos em um contexto de formação científica que permitirá que o mesmo desenvolva e aplique os conceitos adquiridos nas aulas para a produção tecnológica (Meira; Ribeiro, 2016). Dessa forma, no caso deste trabalho, a criação e a montagem de uma estação meteorológica portátil poderá auxiliar o aluno na tarefa de relacionar dados e informações relacionados à Termodinâmica, onde assim o aluno estará lidando com situações do cotidiano. O uso de experimentos práticos nas aulas é importante para que o processo de aprendizagem flua de uma maneira melhor, e no ensino da Física as práticas laboratoriais são imprescindíveis, pois existe a necessidade de comprovar os fenômenos físicos, já que somente com o conteúdo instrucionista dos livros não é possível ter a mesma percepção.

Implementar a Cultura Maker nos Ensinos Fundamental e Médio e na educação em geral torna-se uma estratégia útil no processo de ensino-aprendizagem, pois o atraso da Educação no Brasil está diretamente ligado a deficiência do ensino no país. E sem um bom ensino, temos mais pessoas com dificuldades para entrar em uma universidade ou para se manter na mesma. Na escola, o aluno deveria se tornar apto para iniciar uma vida universitária, contudo sabe-se que isso não ocorre por vários fatores, dentre eles, um Ensino Médio não muito bem realizado (Leite; Fonseca; Lima, 2016). Diante disso, a aplicação da Cultura Maker com a utilização da plataforma Arduino para o ensino interdisciplinar de Física e Programação de Computadores em Linguagem C seria atrativa e educativa para alunos dentre os diversos níveis, tornando o aprendizado mais significativo e fazendo-os enxergar e compreender que a Ciência está em todo lugar e em constante transformação.

Portanto, este trabalho tem como objetivo facilitar o ensino de Física, tendo como estudo de caso aplicações do conceito de Termodinâmica, por meio da Cultura Maker com Arduino para construção de uma estação meteorológica portátil. Dessa forma, esperamos que as aulas de Física saiam do modelo instrucionista, sendo este consistindo apenas numa transmissão de conhecimento, e seja baseada no construcionismo de Seymour Papert (1980), onde o aluno cria e constrói através da exploração e descoberta, tendo o professor como mediador (Ribeiro et al. 2011; Cambruzzi et al. 2015). Ademais, o uso do computador no ensino e aprendizagem de Física diminui a distância tecnológica entre estudantes e escolas, funcionando como um instrumento de laboratório. 
Além desta Introdução, este artigo está estruturado como segue: O Capítulo 2 apresenta aspectos teóricos sobre Cultura Maker com ensino de Física, além de trabalhos relacionados. O Capítulo 3 trata de materiais e métodos utilizados em nossa pesquisa e o Capítulo 4, os resultados e discussões. Por fim, o Capítulo 5 trata da conclusão deste artigo, seguido por suas referências.

\section{Cultura Maker, Ensino de Física e Trabalhos Relacionados}

A Cultura Maker é conhecida como a cultura do "faça você mesmo", que veio do inglês, Do-It-Yourself (DIY). A ideia principal deste movimento é que pessoas de todas as faixas etárias e sem conhecimento especifico consigam planejar, criar, construir, consertar, aperfeiçoar os mais variados tipos de projetos com equipamentos adequados e acessíveis (Meira; Ribeiro, 2016). Esses equipamentos podem ser impressoras 3D, fresadoras, kits de automação como a plataforma Arduino, onde esta é uma das mais baratas e mais utilizadas no meio acadêmico (Arduino, 2020), entre outros. A Cultura Maker já está dentro de algumas salas de aula, assim como nas grandes empresas, ou até mesmo na garagem de casas, fazendo a lógica do "faça você mesmo" um evento tecnológico e coletivo (Hirabahasi et al., 2015).

Ao trabalharmos com a Cultura Maker, esta permite que o aluno seja o protagonista na construção do seu conhecimento com base na aprendizagem prática. $\mathrm{E}$ na nossa abordagem maker, utilizamos o Arduino, que é uma plataforma de prototipagem open-source, possuindo um software multiplataforma que é flexível e de uso facilitado. Com o Arduino é possível criar os mais variados projetos, ambientes interativos, podendo interagir com luzes, roupas, motores, objetos eletrônicos, entre outros. É destinado a artistas, designers, hobbistas e qualquer pessoa interessada em criar objetos ou ambientes interativos. Dessa forma, os projetos que são desenvolvidos com o Arduino podem ser autônomos ou comunicar-se com um computador para a realização de determinada tarefa (Arduino, 2020).

Por sua vez, o processo de ensino-aprendizagem de Física tem que ser apreciável para os estudantes, de forma que estes consigam entender e visualizar que a Ciência e a Tecnologia estão presentes no dia-a-dia em todos os lugares e que mudam constantemente. Ao se ensinar Física, é possível despertar o raciocínio investigativo e crítico de cada estudante, porém isso é possível de acontecer se houver modificações no modo de ensinar (Vidal, 2018). Na visão de Dewey (2010), repaginada para a situação moderna do ensino criativo, globalizado e acessível, não falta experiência na sala de aula, falta sim, sair da sala de aula e ter experiências reais e conectadas. Essa carência de intenção pedagógica na experimentação gera falta de foco, dispersão e descontentamento pelo caminho do ensino. Ainda, a experiência ocasional sem intenção pedagógica concreta, sem objetivos claros, pode gerar resultados frustrantes e dispersos, em um efeito exódico, pois não estabelece conexão com as próximas experiências, tornando-se pura distração ou entretenimento. (Dewey, 2010)

Entre os trabalhos relacionados encontrados ao nosso tema, temos o trabalho de (Leite, Fonseca; Lima, 2016), que utiliza a Cultura Maker e plataforma Arduino na educação e preparação para cursos de engenharia, tendo por base aplicações do cotidiano. O trabalho de Vidal (2016) apresenta uma estação meteorológica para ensino de Termodinâmica com Arduino como um produto educacional. Por fim, o trabalho de Mourão (2018) apresenta o uso da Plataforma Arduino como uma Ferramenta Motivacional para a Aprendizagem de Física, por meio de roteiro de experimentos. $\mathrm{O}$ nosso trabalho permite contribuir com os encontrados na literatura avaliando mais de perto as percepções dos alunos acerca dos experimentos maker, além de possíveis 
ganhos de aprendizado não só em Física, mas em Programação de Computadores. Além disso, diante da pandemia de Covid-19, outro diferencial no nosso trabalho foi a realização do projeto de forma remota, obtendo experiências que servem de contribuições para práticas remotas de ensino-aprendizagem.

\section{Materiais e Métodos Utilizados}

Para executar este trabalho, selecionamos os materiais necessários. Utilizamos o Arduino modelo Uno (Arduino, 2020) conectado ao protoboard no esquema elétrico mostrado na Figura 1. Em seguida, ocorreu a montagem da Estação Meteorológica e o desenvolvimento dos códigos na plataforma Arduino em linguagem C. Para elaborar o circuito inicial que foi utilizado no protótipo em questão, foi obedecido o esquema de montagem mostrado na Figura 1 (simulamos no software Fritzing esta montagem) e para isso se fez necessário os seguintes componentes: 1 protoboard; Jumpers; 1 potenciômetro 10k; 1 display LCD 16 colunas x 2 linhas; 1 sensor de pressão e temperatura BMP 180; 1 bateria 9V; 1 maleta; 1 clip de bateria.

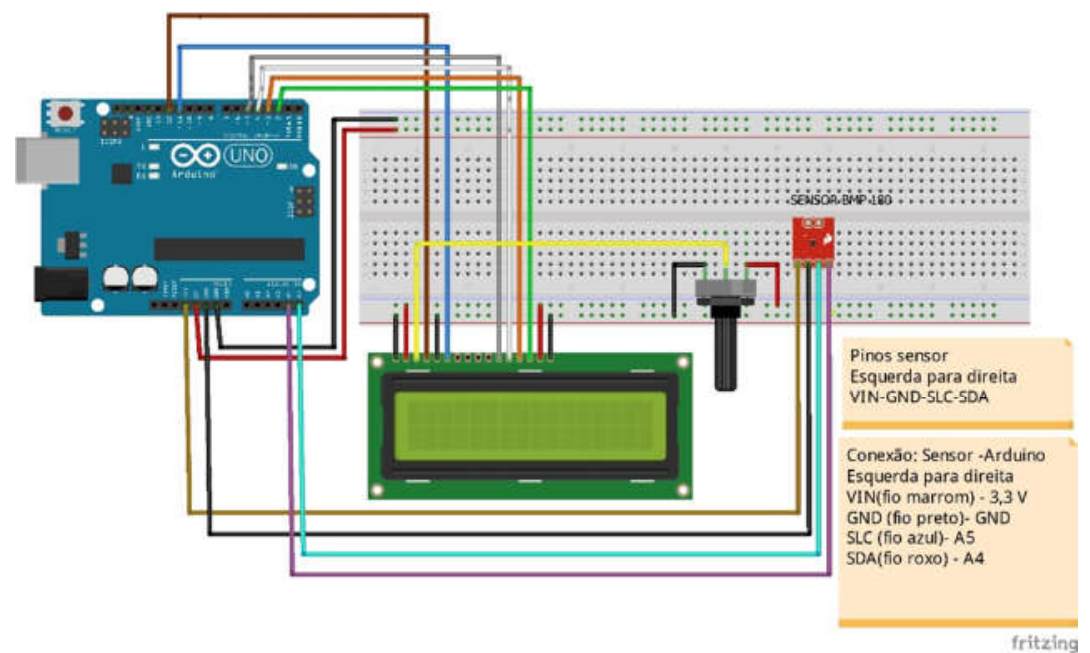

Figura 1. Esquema de montagem utilizado para construção do circuito.

Após a montagem da parte eletrônica, montamos experimentos que simulem equipamentos de medição meteorológica: barômetro, pluviômetro e termoscópio. $\mathrm{O}$ pluviômetro é um instrumento utilizado para a medição da precipitação (chuva). Precisa de um local aberto para realização. Para utilizá-lo, basta colocar em um local arejado, realizando as medições e determinando o valor de precipitação no local. Os materiais utilizados para o pluviômetro foram: Garrafa PET de 2 litros; Fita Isolante; Régua; Corante; Tesoura. O barômetro é o instrumento que mede a pressão atmosférica em cada ponto do ambiente. Para execução do experimento é necessário um lugar arejado, porém sem exposição direta de luz. Os materiais utilizados para o barômetro foram: Tesoura; Fita adesiva; Balão; Copo de vidro; Elástico; Canudo; Régua ou papel milimetrado. Por fim, o termoscópio é um instrumento idealizado por Galileu Galilei que permite verificar o aumento ou a diminuição da temperatura, por meio do deslocamento de um líquido num tubo. Os materiais utilizados para o termoscópio foram: Garrafa pet; Álcool; Mangueira; Régua; Corante.

O barômetro foi construído de forma caseira, utilizando um copo de vidro, metade de um balão para cobrir a parte superior do copo, em que isto é feito desta forma para que o conjunto (copo + balão) funcione como uma membrana que seja sensível a forças externas. Para fazer as medições da variação da pressão foi adicionado um canudo no centro do balão que cobria o copo, mostrado na Figura 2(a). 


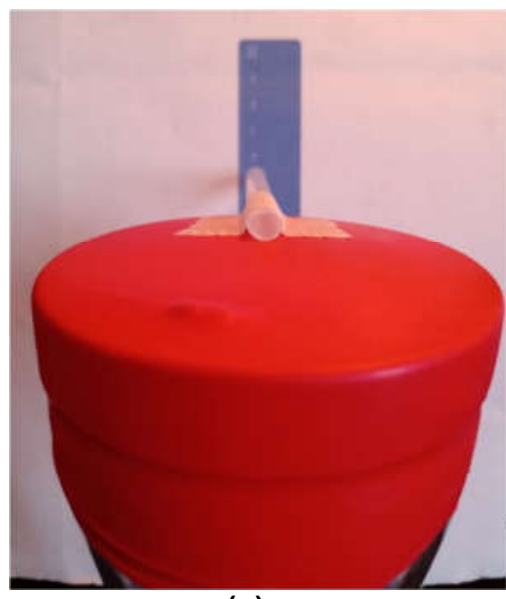

(a)

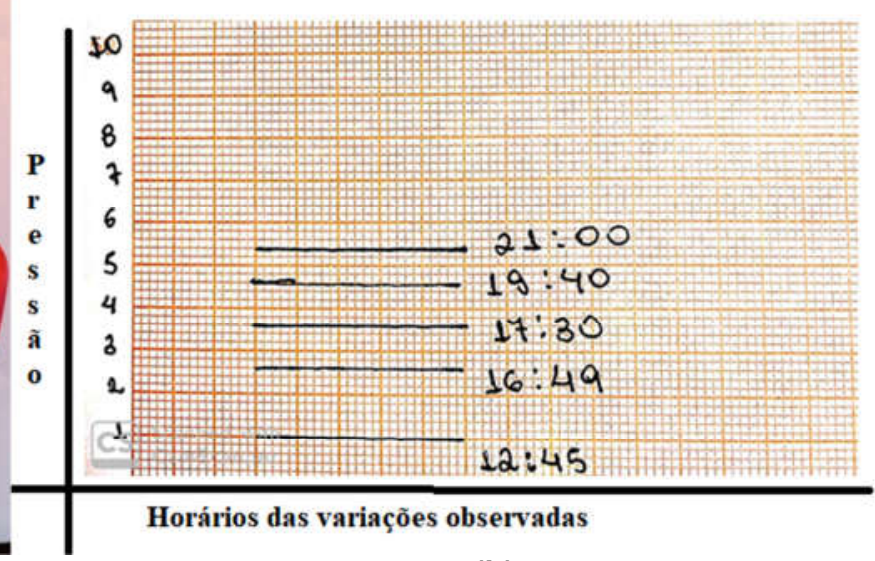

(b)

Figura 2. (a) Barômetro caseiro. (b) Linhas de medições da pressão baseada no horário das variações observadas.

Quanto maior a temperatura, maior é a pressão e quanto menor é a pressão, menor é a temperatura e isso pode ser constatado na Figura 2(b) que tem uma folha de papel milimetrado, que foi nossa referência de variação da pressão. O copo com o balão foi colocado na frente desse papel e marcamos um ponto de origem na folha de acordo com a altura do canudo e a partir disso medimos as variações da pressão nos horários mais quentes na nossa região (Manaus, AM) que foram entre 12:45 e 16:49. Nesse intervalo de tempo, a pressão variou de 1 a aproximadamente 3 , ressaltando que o valor obtido nesse experimento é baseado na variação do canudo ao longo do dia e o instrumento não mostra medidas em Pascal, nem atmosferas. Ele fornece uma forma qualitativa de expressar a pressão do ar. Portanto, é possível observar que o nível mais alto de pressão foi no horário mais quente da nossa região. Quando a pressão externa diminui, as massas de ar presentes no interior do copo impulsionam uma força sobre a membrana criada no copo com o balão, dessa forma gerando uma baixa pressão. (Vidal, 2017).

Por sua vez, o pluviômetro mostrado na Figura 3(a) foi construído com uma garrafa PET, onde a mesma foi cortada na parte superior, de forma que se assemelhe a um funil. Em seguida, foi adicionado água com corante de forma que a garrafa tenha uma sustentação e não caia. Ademais, esse funil foi encaixado na parte inferior da garrafa PET. Também fixamos uma régua para medir o volume do líquido dentro do recipiente. Cada aluno que tinha os materiais fez o seu instrumento em casa e o colocou em um local arejado. Depois, os alunos realizaram as medições e determinaram o valor de precipitação no local em que residem. O cálculo do volume coletado foi feito utilizando conceitos de geometria espacial e plana. O termoscópio mostrado na Figura 3(b) foi feito a partir de um furo na tampa da garrafa PET, onde depois foi encaixada a mangueira de aquário de forma que seja um encaixe perfeito, para que não haja variação no resultado do experimento. Em seguida adicionamos $100 \mathrm{ml}$ de álcool com corante, e para finalizar a construção do instrumento foi fixada uma régua para aferir a variação do líquido.

O teste do termoscópio é realizado em contato com o calor das mãos. Quando a parte inferior da garrafa for aquecida com a temperatura ambiente, ocorrerá o aumento na coluna do líquido. $\mathrm{O}$ aumento do líquido e do gás gera o aumento da pressão, impulsionando o líquido para cima, na região de menor temperatura. Quanto mais alta a temperatura em contato com o instrumento, maior será o deslocamento do líquido dentro do mesmo. 


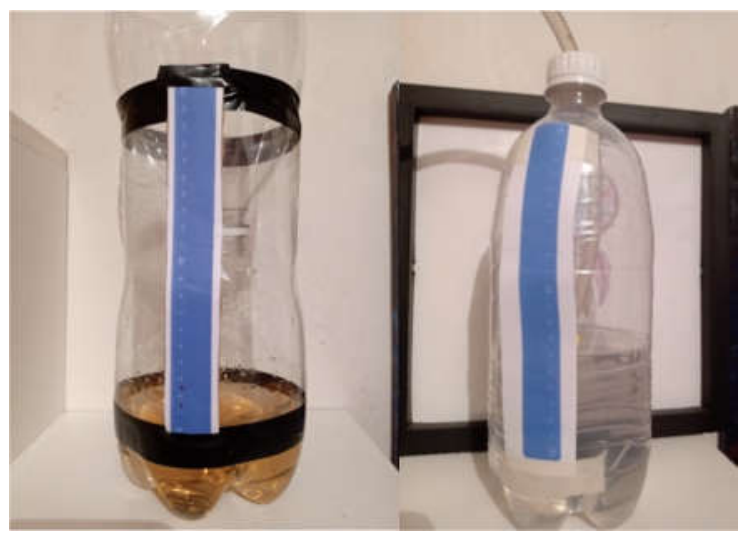

(a)

(b)

Figura 3. (a) Pluviômetro construído. (b) Termoscópio construído.

A relação do circuito feito na plataforma Arduino com estes materiais caseiros montados se dá pela medição e aferição dos valores de pressão e temperatura, a fim de que os alunos associem as variações de pressão e temperatura com os valores medidos pelo sensor no Arduino. Para a montagem do circuito utilizamos o sensor BMP 180, o qual fez as medições de pressão atmosférica e temperatura. Além disso, podemos determinar a altitude. Também foi feita a solda dos pinos de contato no display LCD $16 \times 2$, em que este serve para mostrar os valores de temperatura, pressão e altitude (esses dois se alternavam com o tempo para serem mostrados). Com todos os componentes soldados e tendo o código em linguagem $\mathrm{C}$ para controle da estação meteorológica, se deu continuidade na montagem da estação. Finalizada a montagem do circuito, este foi colocado dentro de uma maleta, de forma que possa ser transportado. A estação meteorológica completa está apresentada na Figura 4. No circuito do sistema físico da estação meteorológica, utilizamos um mini protoboard de 170 pontos que foi acoplado a uma protoshield no Arduino. Essas alterações foram feitas para deixar nossa montagem mais simplificada e mais fácil de ser transportada.

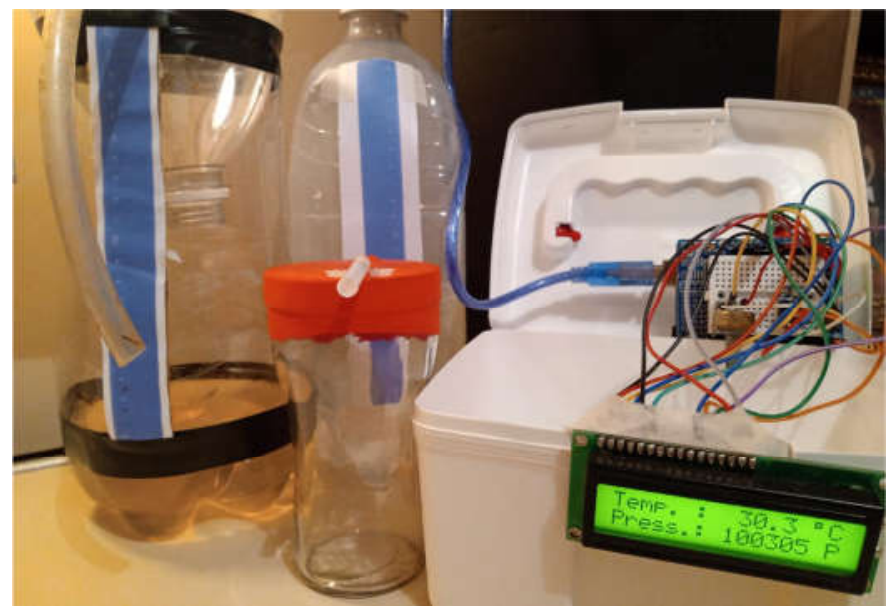

Figura 4. Estação Meteorológica portátil.

\section{Resultados e Discussões}

Realizamos um experimento com 20 alunos do segundo ano do curso do Ensino Médio Técnico em Eletrônica do Instituto Federal do Amazonas Campus Manaus Distrito Industrial (IFAM-CMDI). No experimento, queríamos investigar de que forma a 
Cultura Maker aliada com o Arduino poderia facilitar o processo de ensinoaprendizagem de Física e Linguagem de Programação $C$, de forma que auxilie no aprendizado desses assuntos por meio da criação de uma estação meteorológica portátil com o Arduino. Esses experimentos foram aprovados pelo Comitê de Ética em Pesquisa da Instituição. A priori, iríamos realizar experimentos presencialmente, porém tivemos que aplicar experimentos remotos devido à pandemia de Covid-19.

O roteiro dos experimentos foi como segue, onde os detalhes estarão nos próximos parágrafos. Todos os 20 alunos foram submetidos a um teste inicial a respeito de conceitos de Termodinâmica e Programação de Computadores, a fim de obtermos o diagnóstico inicial destes estudantes. Em seguida, todos os alunos assistiram a uma aula online do professor de Física e por fim, os alunos foram divididos, por meio de um sorteio, em 2 grupos: o grupo que participou dos experimentos maker remotos (10 alunos) e o grupo que não participou (10 alunos). Aplicamos um questionário final para toda a turma, a fim de saber se houve alguma aquisição de conhecimento da turma a respeito dos conceitos de Termodinâmica e Programação de Computadores nos alunos que participaram dos experimentos maker remotos, em comparação aos que não participaram. No total, foram 3 questionários: 1 de diagnóstico inicial, 1 de final e 1 de pesquisa de opinião a respeito dos experimentos maker, sendo este último apenas para os 10 alunos que participaram dos experimentos maker.

Inicialmente, aplicamos o primeiro questionário. No desenvolvimento deste questionário, buscou-se abordar tópicos que estejam relacionados com o experimento. $\mathrm{O}$ questionário, que pode ser visto na Tabela 1, foi disponibilizado no Google Forms e contém 14 questões ( 8 de Física e 6 de programação). $O$ primeiro questionário tinha como objetivo verificar os conhecimentos prévios que os alunos tinham sobre Termodinâmica e Linguagem de Programação. A seguir, será exposta a porcentagem de taxas de erros e acertos de cada questão dos quetsionários. As questões foram feitas para serem respondidas de forma subjetiva, de maneira que o aluno pudesse expor suas ideias. Para verificar as taxas de erros e acertos foram montadas duas tabelas, divididas em perguntas de Física (Tabela 1) e perguntas de Programação (Tabela 2).

Tabela 1. Taxas de acertos e erros relacionados às perguntas de Física no questionário inicial.

\begin{tabular}{|c|c|c|c|c|c|c|c|c|}
\hline Taxas & Q1 & Q2 & Q3 & Q4 & Q5 & Q6 & Q7 & Q8 \\
\hline Acertos & $20,0 \%$ & $70,0 \%$ & $25,0 \%$ & $20,0 \%$ & $45,0 \%$ & $40,0 \%$ & $30,0 \%$ & $9,5 \%$ \\
\hline Erros & $80,0 \%$ & $30,0 \%$ & $75,0 \%$ & $80,0 \%$ & $55,0 \%$ & $60,0 \%$ & $70,0 \%$ & $90,5 \%$ \\
\hline
\end{tabular}

A primeira pergunta feita aos alunos foi: $\mathrm{O}$ equilíbrio do sistema termodinâmico é mantido pela mudança de quais variáveis? E De acordo com a Biomania (2020) a termodinâmica engloba as características gerais dos sistemas físicos em condições de equilíbrio, esse estado pode ser definido por suas variáveis, como pressão, temperatura ou volume, e apenas $20 \%$ dos alunos responderam de acordo com o texto. Já a segunda pergunta se refere a diferença entre o clima e o tempo, que apesar de serem usados como sinônimos, possuem significados diferentes. $70 \%$ dos alunos participantes responderam corretamente.

$\mathrm{Na}$ pergunta seguinte, que era relacionado aos instrumentos utilizados na medição de temperatura, volume e pressão, as respostas obtiveram uma taxa de erro de $75 \%$. Os instrumentos utilizados para medir temperatura, pressão e volume utilizados nesse projeto foram respectivamente o termoscópio, barômetro e pluviômetro. Na quarta pergunta, apenas $20 \%$ dos alunos tinham alguma informação sobre os instrumentos. Instrumentos de medição meteorológica são utilizados para adquirir dados como 
temperatura, pressão, altitude, umidade, entre outros. Quando se une esses instrumentos em um mesmo lugar, temos a estação meteorológica (INMET, 2020). Na quinta pergunta, a maioria dos alunos responderam de forma parecida e errada, com uma taxa de erro de $55 \%$. Na sétima questão $70 \%$ dos alunos não sabiam dizer como era o funcionamento do pluviômetro. A última pergunta relacionada à Física foi sobre a estação meteorológica e se ela faz previsão do tempo, sendo uma das respostas que teve a maior taxa de erro, sendo $90,5 \%$. Para obter dados sobre os conhecimentos sobre Programação dos alunos foram feitas 6 perguntas subjetivas. A Tabela 2 apresenta as quantidades de erros e acertos em \%. Como pode ser visto na Tabela 2 , as taxas de erros tiveram uma porcentagem muito alta, mostrando que o conhecimento de programação dos alunos no momento inicial dos experimentos era praticamente mínimo.

Tabela 2. Taxas de acertos e erros relacionado às perguntas de Programação no questionário inicial.

\begin{tabular}{|c|c|c|c|c|c|c|}
\hline Taxas & Q1 & Q2 & Q3 & Q4 & Q5 & Q6 \\
\hline Acertos & $5,0 \%$ & $15,0 \%$ & $0 \%$ & $5,0 \%$ & $0 \%$ & $5,0 \%$ \\
\hline Erros & $95,0 \%$ & $85,0 \%$ & $100 \%$ & $95,0 \%$ & $100 \%$ & $95,0 \%$ \\
\hline
\end{tabular}

Em seguida, após este diagnóstico inicial, os 10 alunos que participaram da etapa dos experimentos maker assistiram aos vídeos gravados (12 no total), sendo estes: o roteiro do projeto, componentes do projeto, solda dos componentes, montagem da estação com protoboard de 800 pontos, montagem da estação, DIY: Barômetro, DIY: Pluviômetro Caseiro, DIY: Termoscópio, Instrumentos Maker, Teste da Estação Meteorológica, Código Arduino: BMP 180, Aula de física. Todos eles estão disponibilizados no Youtube. Os alunos que tinham os materiais em casa, incluindo os dispositivos eletrônicos e o Arduino, poderiam fazer os experimentos. Os que não tinham, apenas acessavam os vídeos da montagem de cada instrumento e da estação meteorológica.

Depois desta etapa, somente os 10 alunos selecionados para participarem dos experimentos maker responderam a um questionário de pesquisa de opinião. $\mathrm{O}$ questionário foi disponibilizado via Google Forms e possuía 7 perguntas relacionadas a montagem da estação meteorológica e perguntas objetivas de concordância ou discordância em relação a relevância da aplicação do projeto. Realizamos uma pesquisa de opinião a partir de um questionário baseado no Modelo de Aceitação de Tecnologia (TAM) (Davis, 1989), a fim de obter o nível de satisfação dos alunos quanto à facilidade e a utilidade de nossos métodos empregados.

Em relação à percepção dos alunos sobre a facilidade de uso da estação meteorológica portátil com Arduino, $80 \%$ dos alunos concordaram parcialmente que foi fácil aprender a criar e a utilizar a estação, $60 \%$ dos alunos concordaram que é fácil lembrar como se constrói a estação meteorológica portátil com Arduino para aplicações futuras e $70 \%$ dos alunos concordaram que foi fácil aplicar os conceitos de Física e Programação de Computadores vistos em sala de aula com o uso da estação meteorológica. Em relação à percepção dos alunos sobre a utilidade da estação meteorológica portátil com Arduino, 90\% dos alunos concordaram que a estação meteorológica permitiu aprender Física e Linguagem de Programação de uma forma melhor que se estudassem apenas nas aulas teóricas, $80 \%$ dos alunos concordaram que usar a estação meteorológica melhorou os seus conhecimentos na área de Física e Programação de Computadores, 60\% dos alunos concordaram que usar a estação meteorológica foi útil para estimular o interesse na área de automação e também para seguir carreira nesta área. 
Por fim, o questionário final era voltado para todos os 20 alunos da turma, tanto os que participaram dos experimentos maker quanto os que não participaram, de forma que pudesse haver uma comparação com as perguntas do primeiro questionário e entre os que participaram e não participaram dos experimentos maker. Desta forma, o último questionário possui a mesma quantidade de perguntas do questionário inicial. As taxas de acertos e erros dos alunos no questionário final estão apresentadas nas Tabelas 3 e 4 .

Tabela 3. Taxas de acertos e erros relacionados às perguntas de Física no questionário final.

\begin{tabular}{|c|c|c|c|c|c|c|c|c|c|}
\hline \multirow{2}{*}{ Taxas } & $\begin{array}{c}\text { Participaram } \\
\text { dos exps. } \\
\text { maker? }\end{array}$ & Q1 & Q2 & Q3 & Q4 & Q5 & Q6 & Q7 & Q8 \\
\hline \multirow{2}{*}{ Acertos } & Sim & $38,5 \%$ & $50,0 \%$ & $40,0 \%$ & $40,0 \%$ & $55,0 \%$ & $55,0 \%$ & $55,0 \%$ & $25,0 \%$ \\
\cline { 2 - 10 } & Não & $0 \%$ & $20,0 \%$ & $35,0 \%$ & $30,0 \%$ & $25,0 \%$ & $15,0 \%$ & $10,0 \%$ & $0 \%$ \\
\hline \multirow{2}{*}{ Erros } & Sim & $23,0 \%$ & $5,0 \%$ & $15,0 \%$ & $15,0 \%$ & $0 \%$ & $0 \%$ & $0 \%$ & $30,0 \%$ \\
\cline { 2 - 10 } & Não & $38,5 \%$ & $25,0 \%$ & $10,0 \%$ & $15,0 \%$ & $20 \%$ & $30,0 \%$ & $35,0 \%$ & $45,0 \%$ \\
\hline
\end{tabular}

Como pode ser analisado, comparando as Tabelas 1 e 3 houve um aumento significativo das taxas de acertos em geral referente às perguntas de Física, principalmente entre os alunos que participaram dos experimentos maker, o que confirma os resultados positivos da aplicação da estação meteorológica para o ensino de Física. A Tabela 4 apresenta os resultados para as perguntas relativas à Programação.

Tabela 4. Taxas de acertos e erros relacionados às perguntas de Programação no questionário final.

\begin{tabular}{|c|c|c|c|c|c|c|c|}
\hline \multirow{2}{*}{ Taxas } & $\begin{array}{c}\text { Participaram } \\
\text { dos exps. } \\
\text { maker? }\end{array}$ & Q1 & Q2 & Q3 & Q4 & Q5 & Q6 \\
\hline \multirow{2}{*}{ Acertos } & Sim & $20,0 \%$ & $35,0 \%$ & $20,0 \%$ & $20,0 \%$ & $25,0 \%$ & $10,0 \%$ \\
\cline { 2 - 7 } & Não & $10,0 \%$ & $15,0 \%$ & $0 \%$ & $0 \%$ & $0 \%$ & $0 \%$ \\
\hline \multirow{2}{*}{ Erros } & Sim & $35,0 \%$ & $20,0 \%$ & $40,0 \%$ & $40,0 \%$ & $35,0 \%$ & $45,0 \%$ \\
\cline { 2 - 8 } & Não & $35,0 \%$ & $30,0 \%$ & $40,0 \%$ & $40,0 \%$ & $40,0 \%$ & $45,0 \%$ \\
\hline
\end{tabular}

Os resultados obtidos na Tabela 4, apesar de apresentarem taxas de erros maiores que taxa de acertos, teve resultado melhor que os vistos que na Tabela 2. Portanto, a aplicação do projeto com a utilização da cultura maker para ensino de Física e Lógica de Programação trouxe bons resultados, mesmo que na parte de Programação não tenham sido obtidas melhorias expressivas, visto que curiosamente houve maiores taxas de erros a respeito da Programação entre os alunos que participaram dos experimentos maker. Acreditamos que estes resultados poderiam ser melhores se tivessem ocorrido de forma semipresencial ou presencial ou até mesmo se todos os alunos tivessem o Arduino em suas casas, para aprenderem praticando a programação, visto que ele é menos acessível do que os materiais para fazer os medidores caseiros.

\section{Conclusão}

Este projeto desenvolveu a partir da Cultura Maker uma estação meteorológica portátil para prover uma interface entre os conceitos de Física (em especial, a Termodinâmica) obtidos nas salas de aula e a realidade do cotidiano, relacionando ainda os conhecimentos de Programação de Computadores para alunos de Ensino Médio. Isso é possível com a disponibilização de ferramentas de programação ainda mais simplificadas, como a plataforma Arduino, para que professores e estudantes de níveis Médio e Superior possam realizar atividades envolvendo Algoritmos e Linguagem de Programação. Levando-se em conta o baixo custo e a facilidade de manuseio da plataforma Arduino, acreditamos que esta plataforma poderá contribuir como mais uma ferramenta de aprendizagem que possibilitará 
o desenvolvimento de competências de forma interativa, contribuindo para a aprendizagem efetiva dos alunos em áreas do Ensino Profissional e Tecnológico. Os resultados obtidos mostram que houve grande aceitação por parte dos alunos que utilizaram a estação meteorológica. Entre as limitações do trabalho, apenas 20 alunos de toda a turma de 40 alunos tiveram acesso garantido à Internet, podendo participar dos experimentos remotos e sendo considerados para as análises. A Estação Meteorológica desenvolvida foi útil para o aprendizado do aluno que pretende obter conceitos e práticas de Física, Algoritmos e Linguagem de Programação, onde qualquer instituição de ensino pode reproduzir os passos e métodos aqui apresentados, com as adaptações que convierem (inclusive de forma presencial, onde é mais fácil adaptar experimentos remotos para presenciais do que o inverso). Como trabalhos futuros, pretendemos aprimorar nossa estação como um produto educacional, fazendo parte de um conjunto de projetos de aprendizagem para atividades maker interdisciplinares.

\section{Agradecimentos}

Este trabalho recebeu o apoio do Programa de Apoio a Iniciação Científica (PAIC) da Fundação de Amparo e Pesquisa do Estado do Amazonas (FAPEAM)

\section{Referências}

Arduino. Arduino Uno Rev3. Disponível em: < https://store.arduino.cc/usa/arduino-uno-rev3>. Acesso em julho de 2020.

Biomania. Termodinamica. Disponível em: $<$ https://biomania.com.br/artigo/termodinamica\#: :text=Qualquer\%20sistema $\% 20 \mathrm{f} \% \mathrm{C} 3 \% \mathrm{~A}$ Dsico $\% 2 \mathrm{C} \% 20$ seja $\% 20$ ele,press $\% \mathrm{C} 3 \% \mathrm{~A} 3 \mathrm{o} \% 2 \mathrm{C} \% 20$ temperatura $\% 20$ ou $\% 20$ composi $\% \mathrm{C} 3 \%$ A7\%C3\%A3o\%20qu\%C3\%ADmica.>. Acesso em julho de 2020.

Cambruzzi, E.; Souza. R. M.; (2015). Robótica Educativa na aprendizagem de Lógica de Programação: Aplicação e análise. Anais do XXI Workshop de Informática na Escola

(WIE).

Davis, F. Perceived usefulness, perceived ease of use, and user acceptance of information technology. MIS Quarterly, p. 319-340, 1989.

Dewey, J. Experiência e educação: textos fundantes de educação. Petrópolis: Vozes, 2010.

Hirabahasi, G. et al. Movimento Maker. Disponível em: $<$ http://infograficos.estadao.com.br/e/focas/movimento-maker/> Acesso em maio de 2020.

INMET. Instrumentos Meteorológicos. Disponível em: $<$ http://www.inmet.gov.br/portal/index.php?r=home/page\&page=instrumentos $>$. Acesso em julho de 2020.

Leite, S.J.O.; Fonseca, W.S.; Lima, D.S. Cultura Maker: Implementação da plataforma Arduino na educação e preparação para cursos de engenharia. In: XLIV Congresso Brasileiro de Educação em Engenharia. UFRN, RN, 2016.

Meira, S. L. B; Ribeiro, J. L. P. A Cultura Maker no ensino de física: construção e funcionamento de máquinas térmicas. Fab Learn Brasil, Brasília, 2016.

Mourão, O. S. Uso da Plataforma Arduino como uma Ferramenta Motivacional para a Aprendizagem de Física. 2018. Dissertação (Mestrado em Ensino de Física) - Instituto Federal De Educação, Ciência E Tecnologia Do Ceará - IFCE, Ceará, 2018.

Papert, S. Mindstorms: Children, Computers, and Powerful Ideas. Basic Books, 1980.

Resnick, M. Aprendizagem criativa: por uma educação mais expressiva, mão na massa e relevante para todos. Porto Alegre: Penso, 2020.

Santos, J. A; França, K. V; Santos, L, S. B. Dificuldades na Aprendizagem de Matemática. Monografia - Centro Universitário Adventista de São Paulo - São Paulo, 2007.

Vidal, R. Ensino de Termodinâmica através da construção de instrumentos de medição de variáveis meteorológicas e da confecção de miniestação meteorológica portátil com Arduino. Dissertação (Mestrado em Ensino de Física) - UFRN, Natal, RN, 2018. 